\title{
Construction and Research of Internet+ Experimental Teaching Platform Based on Artificial Intelligence
}

\author{
Shuangyuan $\mathrm{Li}$ \\ Jilin Institute of Chemical Technology \\ Jilin City, Jilin Province, China \\ Email: lsy@jlict.edu.cn
}

\begin{abstract}
The research of Internet + experimental teaching platform based on artificial intelligence makes full use of artificial intelligence, WEB technology and Internet + to transform and improve the traditional experimental teaching. Through JAVA, HTML and Python and other languages to build a one-card system, intelligent access control and electronic control system, teaching management system, intelligent monitoring system, Internet experimental reservation system.
\end{abstract}

Keywords-Artificial intelligence; Experimental teaching; System

\section{INTRODUCTION}

Artificial Intelligence is short for AI. In essence, it is a simulation of human consciousness and thinking, hoping to think like human beings and even beyond human intelligence. Today, driven by the strong demand for economic and social development, artificial intelligence is developing exploitatively in foreign countries. Some experts even predict that artificial intelligence will soon become a new engine of world economic development and reintegrate global resources.[1]

Research on Internet+ experimental teaching platform based on artificial intelligence makes full use of artificial intelligence technology and Internet+ to transform and improve traditional experimental teaching. So as to avoid the dilemma that college experimental teaching and experimental conditions cannot meet the needs of college students. [2]There are some problems in university laboratories and their experimental teaching systems, such as lack of independent innovation experimental ability, low utilization efficiency of experimental equipment resources, low level of experimental informatization and low level of laboratory management.

\section{THE GOAL AND STRUCTURE OF THE INTERNET+ EXPERIMENTAL TEACHING PLATFORM}

\section{A. The goal of Internet+ experimental teaching platform}

Taking artificial intelligence and the WEB as the technology springboard, through the traditional approach of Internet + , the traditional experimental teaching is reformed, aiming to enhance the teaching efficiency of traditional college students' experimental teaching, strengthen the operational ability of college students and the experimental success rate, and improve the use efficiency and management level of the laboratory.[3]

We will optimize the scientific and technological innovation system in the field of artificial intelligence in universities, improve the talent training system in the field of artificial intelligence, and promote the transformation and demonstration application of scientific and technological achievements in the field of artificial intelligence in universities. The organic combination of artificial intelligence and Internet+ experimental teaching, on the one hand, further implement the application requirements of artificial intelligence in colleges and universities, and on the other hand, provide experience accumulation and effective attempts for the transformation of innovative experimental teaching mode in colleges and universities.

\section{B. The structure of the Internet+ experimental teaching platform}

Through the understanding of the current laboratory, it is found that there is a lack of modern technology in the traditional laboratory. The combination of artificial intelligence and experimental teaching is an innovative mode. The Internet+ experimental teaching platform is divided into five systems.[4]

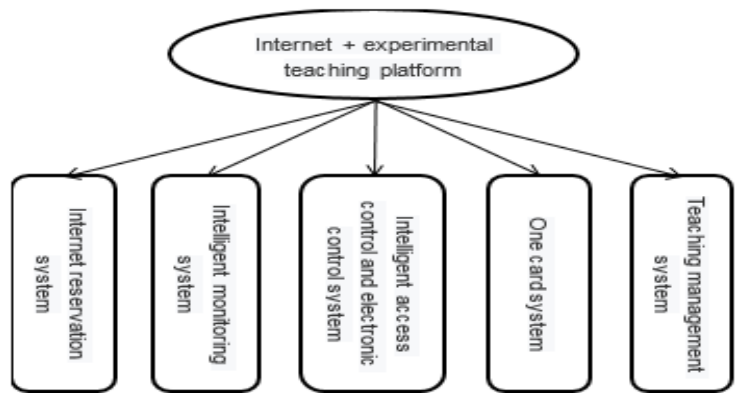

Fig. 1. The structure chart of the Internet+ experimental teaching platform of artificial intelligence
Fund projects: The "13th Five-Year Plan" for Education Science in Jilin Province "Research on Internet+ experimental teaching innovation model of artificial intelligence” (approval no GH180442). 


\section{SYSTEM FUNCTION AND RATIONALITY}

A. The main functions of the Internet+ experimental teaching platform for artificial intelligence are as follows:

- The Internet reservation system can realize students' online course selection and reservation.

- The intelligent monitoring system can monitor all the operations of students in the laboratory, and teachers can watch all the conditions happening in the laboratory online.

- Intelligent access control and electronic control system can complete the management of people entering and leaving the laboratory and the warning of dangerous people, and realize the control of all electronic control equipment.

- One-card system, which can control access control, check-in, equipment use, computer operation, lighting, data and other resources.[5]

- The teaching management system can realize timely delivery of task release by teachers, correct use of video release by equipment, timely submission of students' homework and timely answer of questions.

\section{B. The rationality of the Internet+ experimental teaching} platform:

- Internet reservation system: the laboratory equipment is limited, but there are a large number of students. Students can make an appointment online, so the teacher can clearly understand the number of students who have made an appointment online and arrange students' experiment time reasonably. Students can also choose their favorite experiment courses online.

- The intelligent monitoring system: the laboratory is a particular environment for a variety of experimental work, in order to ensure that the laboratory system running safely and reliably, real-time monitoring, monitoring laboratory environment parameters, guarantee the stability of laboratory condition, and in an accident or malfunctioning of the system automatically take some protection measures.[6]

- Intelligent access control and electronic control system: the laboratory belongs to an open area. The identity of personnel entering the laboratory is identified by the intelligent access control system. If outsiders break in, sound and light alarm will be issued. The use of equipment in the laboratory may be dangerous due to improper operation, and the intelligent electronic control system can timely power off to avoid dangerous occurrence.[7]

- One-card system: one-card is an application that provides access control, attendance, check-in, visitors and information inquiry services with one card and one set of platforms. The card data is stored in a database, the basic information of the card is Shared, and the whole system can issue the card and report the loss once, so as to achieve the real cartoon and netcom.[8]

- Online booking and answer: every time into the laboratory teachers need to show students how to use the equipment, also need to decorate a task, the unnecessary waste of time in class, after students complete the writing board reports, but is not able to save for a long time is easy to lose, can solve through the teaching management system, provides convenience for students and teachers.

\section{THE SPECIFIC IMPLEMENTATION}

\section{A. The Internet realizes the reservation system}

1) The user needs

a) The student needs

- Provide reservation resource inquiry, reservation experiment and reservation cancellation, etc.

- Realize experiment number sequence and timesharing reservation.

b) The school needs

- Upload lab and teacher scheduling information.

- Schedule adjustment and information release.

- Realize SMS notification from teachers and students.

- Booking student information entry.

- Statistical analysis of the appointment experiment.

- Students who have too many cancellations within the specified time will automatically suspend the reservation service for a certain period of time.

\section{2) The user process}

Using SSM framework based on JAVA language and based on the front end of the HTML language, users in the Internet booking system of web page request, the administrator will receive the request, through code realization of database operations, for checking the user from the information, after the audit returns the response information on the user's request. The specific course booking process of users is shown in Fig. 2.

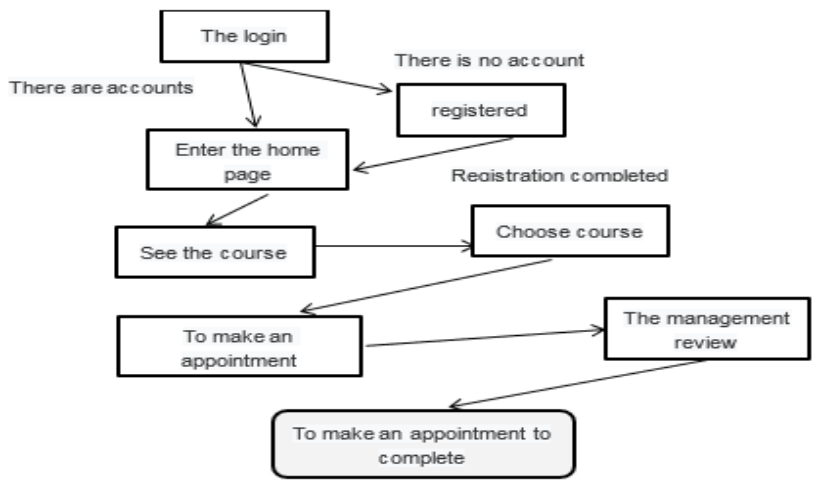

Fig. 2. Flow chart of the Internet reservation system 


\section{B. Intelligent monitoring system}

Using PLCBUS technology, combined with TCP/IP local area network communication technology, GSM module remote communication technology and RS232 serial communication technology, this paper designs and realizes a cable-free intelligent monitoring system for university laboratories that integrates electrical equipment monitoring, networked computer monitoring, security probe monitoring, remote monitoring, alarm and other functions. As shown in Fig. 3.

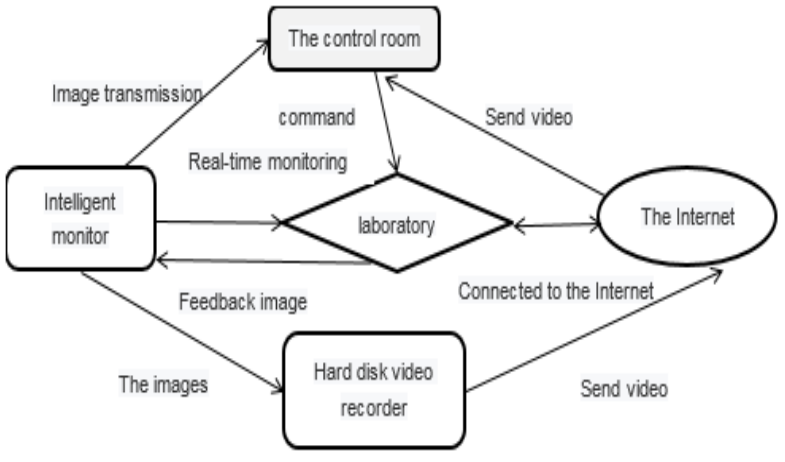

Fig. 3. Flow chart of the intelligent monitoring system

\section{Intelligent access control and electronic control system}

1) Intelligent access control system requirements

- Face recognition

- Voice prompt function

- Automatic alarm

- Liquid crystal display

- Card reader

2) Electrical control system requirements

- Can sense circuit hazards

- Power off operation

3) The flow chart of intelligent access control and electronic control system is shown in Fig. 4.

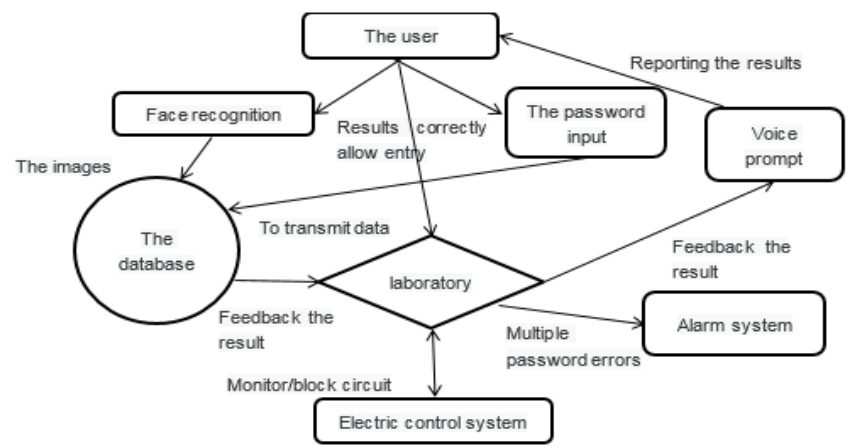

Fig. 4. Flow chart of intelligent access control and electronic control system

\section{One-card system}

The smart laboratory one-card system needs to be connected with the Internet, access to the laboratory, use of laboratory equipment and check-in operations can be completed with one-card. The one-card system includes an access control management system, computer management system, equipment startup system and attendance management system, as shown in Fig. 5.

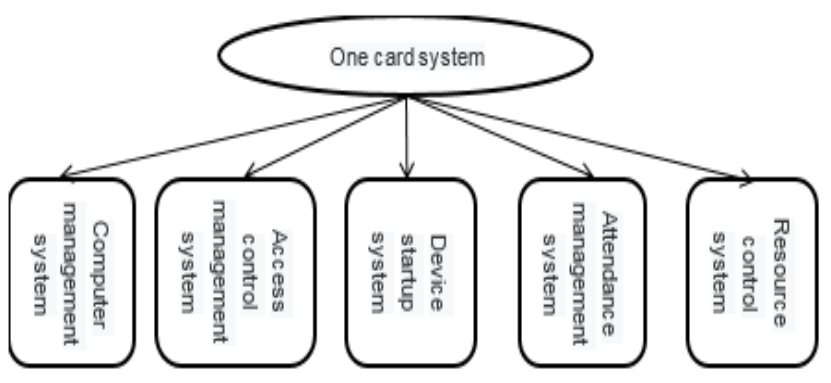

Fig. 5. ER diagram of the one-card system

\section{E. Teaching management system}

Based on SSM framework technology, the student-oriented and teacher-led teaching management system provides the management of teaching contents between teachers and students, including student question asking, student homework submission, teacher task release and teacher experimental operation video.[9] As shown in Fig. 6.

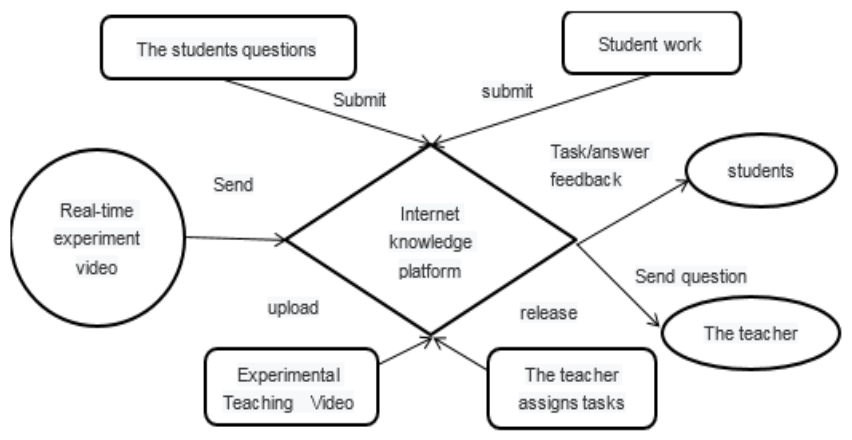

Fig. 6. Internet preview and q\&a ER chart

\section{CONCLUSION}

This paper completes the design and process of the platform system. In this platform, I prefer to study the Internet reservation system and teaching management system, both of which are developed based on the SSM framework, and complete the basic operation of adding, deleting, changing and checking based on the organic combination of JAVA platform and database. An innovative Internet+ experimental teaching platform will be formed in the new era by integrating the onecard system, intelligent access control and electronic control system, teaching management system, intelligent monitoring system and Internet experimental reservation system. The implementation of this platform will improve the traditional laboratory greatly. Comprehensive artificial intelligence and Internet + related research, the combination of traditional experiment teaching mode and the urgent need of renovation to determine the problem points, functional design, process design, set up mathematics model, program based on the python, SSM, HTML language, by constructing a decision tree, logistic regression, the SVM and ID3 algorithm is a combination of 
collection plans to create a new algorithm, is applied to the shallow and deep neural network combination of neural network, and construct the initial framework, supplemented by SQL Server Data Tools for integrated environment. In the research process, I have not been exposed to a lot of knowledge. Through continuous learning, I have a certain understanding of the JAVA language and some foundation of ER graph construction, but there are still many deficiencies to be solved[10].

\section{REFERENCES}

[1] Xianmin Ma, Sheng Chang. Research on the application of artificial intelligence technology in university laboratory management system[J]. China New Communications,2019, (06):107.( In Chinese)

[2] Liang Du, Weijun Zhao, Yue Jin, Ting Guo, Shuanglu Quan. The new model of basic experiment teaching of mechanical design under the background of "Internet+"[J]. Laboratory research and exploration, 2017,36(12):143-146. ( In Chinese)

[3] Quinn, John, Frias-Martinez, Vanessa, Subramanian. Lakshmi Narayan. Computational Sustainability and Artificial Intelligence in the Developing World[J]. AI Magazine, 2014,35(3).
[4] Luciano Specht. Oleg Khatchatourian. Application of artificial intelligence to modeling asphalt-rubber viscosity[J]. International Journal of Pavement Engineering, 2014, 15(9).

[5] Hui Xia, Xiaoli Kong, Ping Li. Research on the cultural construction of economic management laboratory under the background of Internet+[J]. Laboratory research and exploration, 2017, 36(08): 169-172. ( In Chinese)

[6] Haiquan Chen, Kuizi Lin. Research on information-based laboratory management innovation in universities [J].Experimental technology and management, 2016, 33(11):250-253. ( In Chinese)

[7] Qian He. Research on the development of artificial intelligence technology [J]. Electronic information technology, 2016(02). (In Chinese)

[8] Yingxin Tian, Haixia Xue, Analysis of the development prospect of electrical automation based on artificial intelligence technology [J].Electronic technology and software engineering, 2017. ( In Chinese)

[9] Huawei Xu. Design and implementation of experimental teaching management system in universities under the concept of "Internet+"[J]. Laboratory Science, 2017,20(02):60-64. ( In Chinese)

[10] Qinfeng Li, Xiangli Zhang. Discussion on management innovation of liberal arts laboratory in universities under the new normal [J].Science and technology of Chinese universities, 2016(03):18-20. ( In Chinese) 